\title{
An Analysis of the role of context in meaning and interpretation of Gîkûyû Idioms
}

\author{
Peter Ngugi ${ }^{1}$, Dr. Anashia Nancy Ong'onda ${ }^{2}$
}

\author{
${ }^{1}$ School of Social Sciences, Department of Languages and Humanities, Mount Kenya University, Kenya \\ ${ }^{2}$ School of Humanities and Social sciences, Department of Languages and Linguistics, Machakos University, Machakos, Kenya
}

\begin{abstract}
This paper analyses the role of context in the meaning and interpretation of Gîk̂ŷu idiomatic expressions. The paper is based on the premise that the polylexemic nature of an idiom makes it unamendable to structural manipulation and that meaning is context based. This makes it to constitute a linguistic phenomenon that has proved to be problematic to linguistic theory. This paper applied the relevance theory by Wilson and Sperber (1986/1995). To achieve the objective of the study, the study employed a descriptive research design. The target population was 50 native speakers of Gîkûyû language from Ndeiya Sub-county, Kiambu County aged 60 years and above. The participants were sampled using purpose and quota sampling. The study analyzed 100 idioms. The research instruments included interview schedule and focus group discussions. Data was analyzed qualitatively where the idioms were grouped basing on content and themes. The findings of the study reveal that the structure of Gikuyu idioms is unique and the meaning of idiomatic idioms is context dependent.
\end{abstract}

Keywords-Idiom, Context, Gikuyu language.

\section{INTRODUCTION}

An idiom is any groups of words whose meaning cannot be deduced from the meaning of the individual words (Healey, 1968). That is to say, an idiom is an expression that means something different from its words seems to suggest (cf. Sanchez Beneto, 1977). In factHockett, (1958) notes that one can only comprehend the meaning of an idiom within a given context and it is conventional.Thus, an idiom is a common word or phrase which means something different from its literal meaning but can be understood because of their popular use and context.Moreover, the constituents of the lexemes of idioms do not contribute to their meaning. Carter (1987) defines idioms as special combinations with restricted forms and meaning that cannot be deduced from the literal meanings of the words which make them up. Accordingly, an idiom is learned and used a single unit.

Idioms are context dependent (Langacker, 1968) and context has a substantial impact on idiom comprehension (Armstrong, 2005).Context is a concept that is studied in linguistics within the framework of pragmatics. Pragmatics is a branch of linguistics concerned with the use of language in social contexts and the ways in which people produce and comprehend meaningsthrough language. According to Armstrong (2005) idioms are varied and each one has a specific context to occur and their uses are lightly related to the functions they will fulfill in discourse.There are three aspect of context; linguistic, situational and culture.

This paper analyzesGikuyu idiomatic expressions with a close relation to context.Gikuyu is a language in the Central Bantu branch of the Niger-Congo family spoken primarily by the Gikuyu people of Kenya (Macharia, 2011). Gikuyu language is currently spoken in the central region of Kenya. Gikuyu speakers are also found in Nairobi, Rift valley, Coast and other parts of the country where it is spoken. The Kenya National Census in 2009 noted that, the Gikuyu speakers are the most populous ethnic group estimated to a total of 6.5million. The National African Language Resource Centre records that Gîkûyû is one of the most written languages in Kenya. Some of the studies on Gikuyu language include:Barlow (1960) studies the Gîkûyû grammar with reference to various syntactic categories showing various noun classes and adjectives in Gikuyu.Kabira (1993)studies the image of Women in Gikuyu Oral Narratives and observes that in the African context, ordinary people are 
carriers and transformers of oral art. Mbugua (2000) looks at a critical analysis of disaster motif in Gĩkũyũ oral narratives. Muchemi (2009) did a pragmatic study on implicit and explicit speech acts in Gîkũyũ about interpersonal communication. The study looked at the speakers intended meaning which is the performative meaning of an utterance. Gathogo (2013) evaluated the translation of neologisms in Gĩkũyũ radio broadcasts as they are translated by Gĩkũyũ radio presenters. He explored the coinage of Gîkûyû words or phrases due to development in technology among other factors. The above literature provides the researchers with relevant content on Gikuyu language and moreso on Gikuyu oral art. The present paper will focus on interpretation of idioms with a close relation to context.

\section{THE RELEVANCE THEORY}

This paper applied the relevance theory as the tool for analysis. The relevance theory was started and developed by Sperber and Wilson (1986/1995). Relevance theory is a theory that is chastised on one of Grice's central claims: that an essential feature of most human communication, both verbal and non-verbal, is the expression and recognition of intentions (Grice, 1989). Thus, any utterance should automatically create expectations which guide the hearer towards the speaker's meaning. This theory is an approach to the study of human communication which is grounded on a view of human cognition and mind (Moreno, 2007). One of the principles of relevance theory is cognitive principle of relevance. The theory is grounded on the assumption that our minds have evolved in the direction of increasing efficiency and are now set up so that they tend automatically to maximize relevance. According to relevance theory any new information whether derived from external stimuli (utterances, sounds) or form internal representation (thought, memory, inference) will be relevant to an individual if it yields some positive cognitive effects when processed in context (e.g. by answering a question, confirming a hypothesis, correcting a mistake, etc.).

Moreno (2007) states that the processing effort is the effort of perception, memory and inference required to represent an input access to contextual information and derived positive cognitive effects by a number of factors as varied as legibility syntactic complexity, audibility, familiarity with particular dialect, register, style or construction, the accessibility of contextual assumptions and the effort of imagination involved in constructing context etc. On this approach the relevance of an input to cognitive process is a positive function of the positive cognitive effects achieved in processing this input and negative function of the processing effort required to achieve these effects. Moreno (2007) adds that the most basic theoretical claim of Relevance Theory is that human cognition, having evolved towards increasing cognitive efficiency is now geared to the maximization of relevance. That is, it is geared towards striking the best balance between cost and effects and so to achieving the greatest cognitive effects for the least processing effort.

The second principle of this theory is relevance and Communication. The fact that ostensive stimuli create expectations of relevance follows for the cognitive Principle of Relevance. An ostensive stimulus is designed to attract the audience's attention. By producing an ostensive stimulus, the communicator therefore encourages her audience to presume that it is relevant enough to be worth processing. Even a selfinterested deceptive or incompetent communicator manifestly intends her audience to assume that her stimulus is relevant enough to be worth processing. Why else would a listener pay attention? This is the basis for the second or communicative principle of relevance. Sperber and Wilson (1995) point out that the account of communication has practical implications for pragmatics. The overall task inferring the speaker's meaning may be broken down into a variety of pragmatic subtasks. There may be implicatures to identify, illocutionary indeterminacies to resolve, metaphors and ironies to interpret. All these require an appropriate set of contextual assumptions, which the hearer must apply. The communicative principle of relevance suggests a practical procedure for performing these subtasks and constructing a hypothesis about the speaker's meaning.

The third principle is relevance and comprehension. In relevance theory in the identification of explicit content is seen as inferential and equally guided by the communicative equally principle or relevance as the recovery of implicatures. The relevance theoretic comprehension procedure applies in the same way to resolving linguistic under determinacies at both explicit and implicit levels. The hearer's goal is to construct a hypothesis about the speakers meaning that satisfies the presumption of relevance conveyed by the utterance. The overall task can be broken down into a number of subtasks. A subtask is the overall comprehension process. Relevance and comprehension involves constructing an appropriate hypothesis about explicit content (explicatures) via decoding disambiguation, reference resolution and other pragmatic enrichment 
process.Constructing an appropriate hypothesis involves the intended contextual assumption (implicated premises).

This theory shows the relevance of context of a concept on a given occasion of use inconstructing a range of information.According to Wilson and Sperber (2004) the linguistic context and accessibility of assumptions one will assemble for a given concept or a given occasion are relevance driven. This paper considers that the use of idioms in a particular context is relevantly driven.

\section{RESEARCH METHODOLOGY}

This analysis adopted a descriptive research design. Descriptive research design allows for discovery of the unexpected and in-depth investigation of the given problem (Kothari, 2004). Descriptive research design was used in this study and it enabled the researcher to obtain information that described existing phenomena by asking individuals about their perception, attitudes, behavior and values. The study was carried out in Ndeiya, Kikuyu sub-county in the western part of the Kiambu County. This study targeted to collect data for this research from native speakers of Gĩkũyũ of varying age, gender, education levels and religious denominations. The age bracket preferred was 60years and above.The study used two data collection instruments namely, interviews and focused groups. The study was guided by the following research objective:

i. To determine the role of cultural context in the interpretation of Gikuyu Idioms.

ii. To determine the role of linguistic context is important in the interpretation of Gikuyu Idioms.

iii. To determine how situational context is important in the comprehension of Gikuyu Idioms.

\section{RESULTS AND DISCUSSION}

\subsection{The role of cultural context in the interpretation of Gikuyu Idioms}

Language is a central aspect of culture (Kramsch, 1998). Language expresses and represents culture. This means that language is the vehicle that reveals cultural practices, knowledge and attitudes, together with beliefs and emotions which are basic forms of culture. Language also reflects the cultural behavior and practices are carried out through the medium of language, whether this is verbal or non-verbal.
Language also symbolizes culture since it serves as an expression of identity. Idiomatic expressions are culturally bound. Culture has a crucial role in encoding and decoding messages (Byram and Risager (1999) cited in Al-Issa, (2005). In fact idiomatic expressions convey a unique aspect of culture.Context of culture refers to culture, customs and background of time in language communities in which speakers play a part.

The data collected shows that idioms are a reflection of Gikuyu culture. Hence, they are used as a tool of enculturation of the values of Gikuyu society. The idioms reflect the values that the Gikuyu culture upholds. The data discussed in this section is idioms that are related to the cultural values of a given society. Through focused groups the participants noted that Gikuyu idioms reflect the morals of Gikuyu society. Some of the idioms collected showed the value of generosity which is a virtue and others were on vices like greed as shown below:

\section{Idiom 1:}

\section{Gũtumamũndũrĩgu}

Gloss: Knit someone 'rĩ̃gu'

Idiomatic meaning: to be kind or generous

Idiom 1 reflects what the society expects from the people. Rĩg $\boldsymbol{u}$ here means packed food that people carried when they went for a long journey. However, they were expected to share it even with strangers. This then would reflect or strengthen generosity among them. It is a sign of kindness. Idiom 2 below also shows generosity.

\section{Idiom 2:}

\section{Kwenyũranambocoyagwathĩ}

Gloss: To divide bean once it falls on the ground

Idiomatic meaning: sharing and spirit of unity

Idiom 2 above encourages people to share always what they have. The community believes in the spirit of unity. The idiom is mostly used in times when one is faced with a problem or when the community is going through problems such famine, draught and war. The members of the society are always reminded of unity. Patience is also a virtue that is encouraged as shown below:

\section{Idiom 3:}

\section{KũrĩaMũrĩ}

Gloss - to eat root

Idiomatic meaning: to be patient 
This community is also against vices such as greed, laziness among others as shown below:

\section{Idiom 4:}

\section{Gũikionĩnda}

Gloss: Be led by the stomach

Idiomatic meaning: Greed

This idiom is said to a person who is greedy. Such a person is reminded of the illness of being greedy. This idiom is meant to encourage people to share what they have and it discourages selfishness. Idiom 5 is an idiom that also cautions those people in the society that discourages others from working hard.

\section{Idiom 5:}

\section{Kunwoguoko}

Gloss - to break someone's hand

Idiomatic meaning- to discourage from working

Idiom 6 below further cautions people in this society to be humble as shown:

\section{Idiom 6:}

Kũmiamũtwe

Gloss- to harden the head

Idiomatic meaning: to be stubborn

Idiom 5 and 6 below warns people that are unappreciative and ungrateful. These idioms are common among the elders when they advise young people to be appreciative and grateful always since they may not know what the future holds for them.

\section{Idiom 7:}

\section{Kũmĩakĩraro}

Gloss: To defecate on the sleeping place

Idiomatic meaning: Being unappreciative

\section{Idiom 8:}

\section{Kũrĩagĩthũrikĩiniĩ}

Gloss: To eat when the chest is upside down

Idiomatic meaning: To be ungrateful

Some of the proverbs that also reflect the Gikuyu culture include:

\section{Idiom 9:}

\section{Gũtuĩramatagĩthũri}

Gloss: To spit on the chest

Idiomatic meaning: to bless

Idiom 9 above is mostly used by the elderly especially when they are performing the ritual of blessing the young. The elders are fond of spitting on their chest as a sign of blessing or a curse. Another cultural context where the elders use idioms is in situations where the members of the society are encourage to keep the secrets of the society as shown in idiom 10 and 11 below:

\section{Idiom 10:}

\section{Kuoniamũndũnjegeke}

Gloss: Show someone armpit

Idiomatic meaning: To expose secrets

\section{Idiom 11:}

\section{Kwĩraniramĩatũ}

Gloss: Tell others of hives

Idiomatic meaning: To expose secrets

The data on Gikuyu idioms show that idiomatic expressions are used to express Culture. The idioms reflect Gikuyu culture and their way of life. Idioms are culturally used to manifest the way of life which is peculiar to Gikuyu community. The language in the idioms is also used in the maintenance of the patterns of life in the society. Idiom 10 and 11 shows what Gikuyu community considers appropriate to the society.Following Scarino (2010) culture is a contextual framework that people use to exchange meaning in communication with others and through which they understand their social world.

\subsection{The role of linguistic context in the interpretation of Gikuyu Idioms}

Linguistic context is a reference to the context within the discourse through its relationship with the words, phrases and sentences of any discourse (Song, 2010).The linguistic context plays a major role in the general system of language. The meaning of the idiomatic expression therefore depends on other units in which the idiomatic expression is used. That is, the idiomatic expression gains its significance basing on what precedes or follows it in a text. The discussion that follows shows how syntactic meaning of an idiom is closely analyzed with close relation to context.

First an idiomatic Expression can function as a Subject in the context of a verbal sentence. The subject is the doer or what the sentence is about. The idioms below show instances 
where the interpretation of the idiom directly relates to the subject of the sentence.

\section{Idiom 12:}

\section{Twacanũrirwo}

Gloss: We were combed

Idiomatic meaning: Being informed

The meaning of this idiom directly relates to the subject of the sentence. The pronoun 'twa' is the plural form of I which means we. The subject of the sentence twa was exposed to the information or news which they did not have and which is helpful to them in that context. Example 13 below further shows a case where an idiom is used as a subject of the sentence:

\section{Idiom 13:}

Twîyohetemûthiorihîndînoya corona.

Gloss: We have tied a belt during this time of corona.

Idiomatic meaning: We are bracing for difficult times during this time due to corona.

Gikuyu is an agglutinative language. Therefore, in the above data the idiomTwîyohetemûthiorihîndînois the subject of the sentence meaning We have braced ourselves for the hard times and in this context the corona pandemic.

Idiomatic expressions were also used as predicate of the sentence. A predicate isthe part of a sentence or clause containing a verb and stating something about the subject. The predicate in a sentence modifies the subject in some way. Since the subject is either the person, place, or thing that a sentence is about, the predicate must contain a verb explaining what the subject does and can also include a modifier. The data collected reflected instances where idiomatic expressions occurred as a predicate. As a predicate the idiomatic expression can consist of a single word, phrase, or full sentence. The data below show the predicate as a single word:

\section{Idiom 14:}

Mwanginîaretirwo

Gloss:Mwangi was called

Idiomatic meaning: Mwangi died.

Gikuyu being an agglutinative language (where words may contain different morphemes) makes the idiomnîaretirwoto appear as single to mean that Mwangi died.

\section{Mwanginîaretirwo}

S / Predicate

In this case then the predicate is a single word. Other idiomatic expressions had a predicate as a phrase as shown below:

\section{Idiom 15:}

KamaunîarauniremburiyaChegekûgûrû.

Gloss:Kamau broke Chege's goat's leg.

Idiomatic meaning:Kamau impregnated Chege's daughter.

Idiom 16 is a case where the idiomatic expression appears as a phrase as shown in the analysis below:

KamaunîarauniremburiyaChegekûgûrû.

\section{S I Predicate}

The idiomatic expression is in form of VP (verb phrase) (nîarauniremburiyaChegekûgûrû.). The meaning of this idiom is well comprehended in line with the linguistic items in the sentence.Idiom 17 and 18 further shows a case where the predicate is a VP.

\section{Idiom 17}

MbûriyaNjenganîranywirekagera.

Gloss:Njenga's goat drank a stone) .

Idiomatic meaning:Njenga's goat got lost/disappeared without a trace

MbûriyaNjenganîranywirekagera

S

/ Predicate

\section{Idiom 18}

Akorwonĩurrendatũgũikĩriemĩtĩnonginyawĩkĩrecoromaaĩ'

Gloss 'If you want us to vote for you, give us something to drink.

Idiomatic meaning: to be corrupted

Akorwonĩũrendatũgũikĩriemĩtĩnonginyawĩkĩrecoromaaĩ'

S

\section{/ Predicate}

The meaning of idiom 17 and 18 directly relates to the linguistic items in the sentences. This then implies that the linguistic context of idioms is a paramount feature in the course of comprehending the meaning of the idiom. The predicatewĩkĩrecoromaaĩ ' becomes an idiomatic expression when it is directly linked to the conditional clause if (Akorwonĩurendatũgũikĩriemĩtinonginya) that is the subject 
of the sentence.The structure of idiomatic expressions also reflects cases where an idiom is an adverbial phrase or a prepositional phrase as shown below:

\section{Idiom 19:}

Ndutanîaratûngirenyoninjûru.

Gloss: Nduta met with a bad bird

Idiomatic meaning: Nduta had bad luck.

Idiom 19 above is a case where an idiomatic expression is a prepositional phrase (pp) in the sentence. In this case the PP completes the meaning of the Verb $(\mathrm{V})$ as shown in the analysis below:

Ndutanîaratûngirenyoninjûru.

\section{S $\quad$ V $\quad$ PP}

Nyoninjûruis the idiomatic expression which is in form of PP (with a bad bad). Idiom 44 below further further shows an idiomatic expression in form of a PP

Idiom 20:

Njeriaronirenakanua.

Gloss:Njeri saw with her mouth) -

Idiomatic meaning:Njeri was surprised/shocked

Idiom 44 is further analyzed below:

Njeriaronirenakanua

S $\quad$ V PP

The PP in the above sentence is the idiomatic expression that gives us more information about Njeri (that is Njeri was surprised/shocked). There are also cases where the idiomatic expression appears as adverbial. In this case the interpretation of the idiom relies on the linguistic items in the sentence. Idiom 21 below is an example where an idiom is an adverbial

\section{Idiom 21}

\section{Wakahareakuireagĩcariangemi'}

Gloss: the pole cat died while seeking praises.

Idiomatic meaning: to seek for praises.

The analysis of idiom 21 is further shown below:

\section{Wakahareakuireagĩcariangemi'}

\section{$S$}

$v \quad$ Adverbial

The idiomatic expression agĩcariangemi' is an adverbial and is said to people who are not self-driven but who do things in order to be seen or be praised.
The above data shows how the meaning and comprehension of idiomatic expressions is closely linked to the linguistic context.

\section{3: The role of situational contextin the interpretation of Gikuyu Idioms}

Situational context is basically the 'context of situation', in which an idiom is used. Situational context relates to the environment of discourse in terms of time and space. It also relates to relationship between participants. Idiomatic expressions are well understood in a given situational context. The data collected established that the participants in the discourse determined the idiomatic expressions used by participants in a particular situation. The first observation was some of idiomatic expressions that were likely to be used by the youths when they are conversing with one another. The youth like complementing each other by use of the following idioms:

\section{Idiom 22:}

\section{Kũũma}

Gloss: to dry

Idiomatic meaning: To be smart

\section{Idiom 23}

\section{Gũcinamwakiwanyeki}

Gloss: to burn grass fire

Idiomatic meaning: Be smartly dressed

Other idioms that are likely to be used by the young generation in their conversation are:

\section{Idiom 24:}

\section{Kũhũũrĩka}

Gloss: to be beaten

Idiomatic meaning: Being bored

\section{Idiom 25:}

\section{Gũtembaũ}

Gloss: to lose timber

Idiomatic meaning: Lose focus/go mad

Idiom 24 and 25 is likely to be used by the youth especially when they are discussing issues related to them. Idiom 24 for instance is typically used when one is bored while idiom 57 is used to describe a person who has lost focus. Other idioms that are likely to be used by the youth include idiom 25 to 30 below: 
Idiom 26:

\section{Kũrũgĩra}

Gloss: to jump on

Idiomatic meaning: To understand or comprehend

Idiom 27:

Kũgũagũa

Gloss: to fall repeatedly

Idiomatic meaning: To change

Idiom 28:

Kunyitamwaki

Gloss: - to catch fire

Idiomatic expression: to be greatly annoyed/ angered

\section{Idiom 29:}

Kwĩhũrirairebe

Gloss: to beat one's own drum

Idiomatic meaning: blow one's trumpets - to boast

Idiom 30:

Kanyakandeto

Gloss: - a calabash of news

Idiomatic meaning: - person who is newsy almost anything

- always has things to say about

- mr/mrs know - all

The above data show how the young participants determine the kind of idioms that may be used in particular situation. The young differ from the old in terms of topic of discussion which determines the kind of idioms that may be used in their discourse. The old on the other hand may have different topic of discussions such as general life, religion, death and marriage that may determine their use of idioms. The topics of discussions determine the context of situations which an idiomatic expression is used. The data below gives some of the idioms that are used by the old:

\section{Idiom 31:}

\section{Gũitaũkĩonoria}

Gloss: to poor as you empty

Idiomatic meaning: to lose everything

Idiom 32:

\section{Kũhenerĩo}

Gloss: - - to be beckoned

Idiomatic meaning- to die

Idiom 33:

Gũkirianjoka

Gloss - to silence the tapeworms

Idiomatic meaning: eat little amount of food

Idiom 34:

\section{Kuna rũkomo}

Gloss: to break the bends

Idiomatic meaning: to talk in parables

\section{Idiom 35:}

\section{kwararũhĩ}

Gloss: - to spread the palm

Idiomatic meaning: to beg

\section{Idiom 36:}

\section{Kuohanda}

Gloss - to tie the stomach

Idiomatic meaning - to conceive/ become pregnant

During the focus group discussion the old participants revealed that idioms were tacit way of expressing abstract ideas in the community. Issues such as death and love are politely expressed by use of idioms. For instance, Idiom 32: Kũhenerĩo ( to be beckoned) is a polite way of saying that someone is dead. Idiom 33: Gũitaũkĩonoria (to poor as you empty) is also a polite way of expressing loss. When someone loses everything it is painful and hence such a person needs support and comfort. Idiom 36: is also a polite way of referring to pregnancyIdiom 36:Kuohanda (to tie the stomach) which has an idiomatic meaning to conceive or become pregnant. The study therefore observes that the older generation uses idioms to express abstract ideas as compared to the young generation. The old also uses idioms as a polite way of expressing ideas they consider as taboo words.

\section{CONCLUSION}

This paper was designed to examine the role of context in the interpretation and comprehension of Gikuyu idioms. The study concludes that Gikuyu idioms are context dependent. The study shows that the meaning of the idiom does not 
literally rely literally on the component of the idiom but on idiomatic construction that is context related. The study also concludes that the meaning of an idiomatic expression relates to the connection between the syntactic and semantic structure through a number of lexical and grammatical devices. Therefore, language plays a crucial part of culture and idioms are condensed to reflect cultural scenes of religion and beliefs. The study therefore concludes that idioms are therefore a cultural vehicle and they are used in a specific situation to convey a specific meaning.

\section{REFERENCES}

[1] Al-Issa, A. (2005). The Role of English language culture in the Omani language education system: An Ideological Perspective. Language, Culture and Curriculum, 18 (3) 258270.

[2] Armstrong, E. (2005). Expressing opinions and feelings in aphasia: Linguistic options. Aphasiology, 19(3/5), 285-296.

[3] Barlow A, R, (1960).Studies in Kikuyu Grammar and idiom. Edinburg: William Blackwood \& Sons.

[4] Carter, R. (1993). Introducing Applied Linguistics. London: Penguim Book.

[5] Gathogo, R. (2013). Translations of neologisms: A case study of Gikuyu radio broadcast. UON: Unpublished MA Thesis.

[6] Grice, H. P. (1989). Studies in the Way of Words. Cambridge MA: Harvard University Press.

[7] Healey, A. (1968). English Idioms. Journal of linguistics society of Papua Guinea, 2 (1) 71-108.

[8] Hocket, CH (1998). A course in modern linguistics. New York: Macmillan.

[9] Kothari, C (2004). Research Methodology: Methods and Techniques (2nd Ed.). New Delhi: New Age International Publishers.

[10] Kramsch, C. (1998). Language and Culture. Oxford: OUP

[11] Langacker, W, R. (1968). Language and Its Structure: Some Fundamental Linguistic Concepts. San Diego: Harcoust Brace Jovanouich.

[12] Macharia, D. (2011). Phonological Variation and Change in Gĩkŭyŭ: A Case Study of Mathira Dialect in Kenya. Unpublished MA Thesis, Kenyatta University, Kenya.

[13] Mbugua, (2000). A Critical Analyses of Disaster Motif in Gĩkũyũ Oral Narratives. Unpublished MA Thesis UON.

[14] Moreno, R. E. V. (2007). Creativity and Convention. Amsterdam: John Benjamins.

[15] Muchemi, L., W. (2009). A Pragmatic study on implicit and explicit acts in Gikuyu. UON: Unpublished MA Thesis.

[16] SachezBenedito. F. (1977). Introduction. DiccionarioConciso de modismos. Madrid: Editorial Alhambra.

[17] Song, L. (2010). The Role of Context in Discourse Analysis. Journal of Language Teaching and Research, Vol. 6 (1) 876879.

ISSN: $2456-7620$

https://dx.doi.org/10.22161/ijels.55.65
[18] Sperber, D \& D. Wilson. (1986).Relevance: Communication and Cognition. Oxford: Blackwell.

[19] Sperber, D \& Wilson, D. (1995). Postface to the second edition of Relevance: Communication and Cognition. Blackwell, Oxford.

[20] Wilson, D and Sperber, D. (2004). Relevance Theory.In Horn, L.R. \& Ward, G. (eds.). The Handbook of Pragmatics, pp.607-632. Oxford: Blackwell. 